\title{
Aspergillus niger Technique for the Bioassay of Manganese
}

\author{
By C. B. SULOCHANA AND M. LAKSHMANAN \\ University Botany Laboratory, Madras-5, India \\ (Accepted for publication 3 August 1967 ) \\ SUMMARY
}

\begin{abstract}
The rates of growth of five strains of Aspergillus niger (M, MUBL I, NRRL 334, NRRL 323, NRRL 346) were followed in an optimum nutrient solution. The time course of growth of all the strains showed a steep decrease after 3 days, except that of strain NRRL 346 which tended to flatten out. A correlation between sporulation and mycelial dry weight was observed. All the five strains showed a marked decrease in mycelial yield in the absence of manganese from the basal medium. Their quantitative responses to graded concentrations of $\mathrm{Mn}$ in the medium were compared with spore and mycelial inocula. Statistical analyses of the result suggest that strain MUBL I is the most suitable test organism for the bioassay of $\mathrm{Mn}$. The effective range of concentrations of Mn which coincided with the maximum differences in mycelial dry weights was $0.00 \mathrm{I}-0.006 \mu \mathrm{g} . / \mathrm{ml}$.
\end{abstract}

\section{INTRODUCTION}

Many attempts have been made in the past two decades to study the need for trace elements for the growth of micro-organisms in general and fungi in particular. The use of fungi as test organisms for the assay of trace metals has come into vogue because of their specific response to deficiency of individual trace metals in the nutrient medium. Several strains of Aspergillus niger have been used in the assay of trace elements under various physical and physiological conditions (Mulder, 1948; Nicholas \& Fielding, 195I; Nicholas, I952; Donald, Passey \& Swaby, I952a; Saraswathi-Devi, I962). The lack of uniformity in experimental conditions has made comparison of the behaviour of various strains to deficiencies of trace metals impossible. Furthermore, since purification of nutrient solutions is an essential prerequisite for obtaining precise deficiency symptoms, attention has been mainly devoted to the methods of purification and little recognition has been given to the fact that comparison between the quantitative response of organisms under physiologically indeterminate conditions would not be of great value. The need for a balanced optimum solution for growth, containing a minimum quantity of constituents and with a composition subject to exact definition on the basis of physiological response was emphasized by Steinberg \& Bowling (1939). Such a nutrient solution provides an accurate basis for the comparison of the quantitative response of different strains of the same organism within a defined physical environment. An optimum nutrient solution has been used in the present work to compare the response of five strains of $A$. niger to a graded range of concentrations of manganese in the nutrient solution with a view to selecting a strain for the bioassay of this element.

Bioassay methods are in general based on the observation that in the absence of an essential mineral element growth is retarded as shown by a decrease in mycelial dry 
weight. Bioassay of manganese has so far been done by visual comparison of mycelial characters and spore cover between the standards and the unknown since decrease in growth in the absence of manganese could not be obtained (Nicholas, 1952) although Steinberg (1939) reported clear-cut decrease in growth of Aspergillus niger in manganesedeficient medium. An attempt was made in the present work to enquire whether it is possible to obtain decreases in mycelial yields in manganese-deficient cultures in an otherwise optimum nutrient solution, by using the purification procedure of Donald et al. (1952b), and whether the growth of the organism is reproducibly and quantitatively proportional to graded increments in the concentration of manganese. When decrease in growth is considered as the criterion for examining the need for a micronutrient element, a knowledge of the rate of growth and the relationship between growth and reproduction is necessary as comparisons are best made during the phase of maximal growth. Hence the rates of growth of the five strains of $A$. niger were also studied.

\section{METHODS}

The following strains of Aspergillus niger were used:

M, Mulder's strain-culture received from Centraal Bureau voor Schimmelcultures, Baarn, Holland.

MUBL I, isolated from soil at the University Botany Laboratory, Madras and used previously in this Laboratory for micronutrient element deficiency studies.

NRRL 334, the original no. Thom. 4247 used by Steinberg in his studies on physiology of Aspergillus niger with special reference to heavy metal nutrition.

NRRL 323, used for soil testing by Niklas \& Hirschberger (1924).

NRRL 346, characterized by abundant production of sclerotia.

The basal medium contained (g./1.): ammonium nitrate, 2.06; monopotassium phosphate, $0.55 ; \mathrm{MgSO}_{4} \cdot 7 \mathrm{H}_{2} \mathrm{O}, 0.25 ;$ sucrose, 50 (Steinberg, 1939). The trace element composition of the medium was as follows (mg./1.): $\mathrm{Fe}, 0.20 ; \mathrm{Zn}, 0.20 ; \mathrm{Cu}, 0.04 ; \mathrm{Mn}$, $0.02 ; \mathrm{Mo}, 0.01$. The basal medium was made up with double-distilled water and was initially purified from trace elements by adsorption with aluminium oxide according to the method of Donald et al. (1952b). The medium at $\mathrm{pH} 7.2$ with $0.5 \%$ (w/v) $\mathrm{Al}_{2} \mathrm{O}_{3}$ (chromatographic analysis grade) was autoclaved at $115^{\circ}$ for $20 \mathrm{~min}$. The medium was swirled while still hot and then allowed to stand overnight; it was then filtered through Whatman no. 42 by gravity filtration. The filtered medium was then adjusted to $\mathrm{pH} 7.5$ and distributed into $100 \mathrm{ml}$. Erlenmeyer flasks; each flask had I $5 \mathrm{ml}$. medium containing the appropriate concentration of trace elements. The trace element stock solutions and dilutions were made in triple-distilled water. The "minus all' trace-elements medium was the purified basal medium without any added trace element, the 'plus-all' medium contained all the trace elements, and the 'minus Mn' medium had all the trace elements except manganese. The media were autoclaved at I $2 \mathrm{I}^{\circ}$ for $\mathrm{I} 5 \mathrm{~min}$. The chemicals used were of the Analar or Merck G.R. grade and water was distilled in all-glass Pyrex stills. All the precautions which were essential for the Aspergillus niger technique (Saraswathi-Devi, 1958) were observed.

Spore inoculum was prepared by shaking 3 loops of spores from 5-day cultures on a potato glucose agar slope into $5 \mathrm{ml}$. of sterile triple-distilled water; each flask received three drops of this spore suspension. Mycelial inoculum was prepared by growing the 
fungus in 'minus all' medium for 3 days. The mycelium was then filtered, washed and broken with Pyrex glass beads in Io ml. of sterile distilled water; three drops of this suspension were added to each flask. The flasks were randomized and incubated at $35 \pm 0 \cdot 2^{\circ}$. The cultures were filtered at appropriate times and the mats dried at $80^{\circ}$ to constant weight.

Since only three replicates could be maintained for each concentration of $\mathrm{Mn}$ in one experiment, the above experiments were repeated and essentially similar results were obtained.

The rate of growth was measured by recording the mycelial dry weight at $24 \mathrm{hr}$ intervals for 6 days. Statistical analyses were done according to Paterson (1939) and the regression analysis was done according to Bailey (196I) and Freeman (1956). The best-fitting straight line $y r=a+b x$ was constructed by the method of least squares, where $b$ is known as the regression coefficient of $y$ on $x$. The test of significance used was the conventional $F$ test at $5 \%$ and $\mathrm{I} \%$.

\section{RESULTS}

The time course of growth of all the five strains was characterized by three distinct phases: (I) a phase of little or no apparent growth extending for $24 \mathrm{~h}$ after inoculation; (2) a phase of rapid and approximately linear growth between 24 and $72 \mathrm{~h}$; (3) a phase of no net growth or of decrease in dry weight after $72 \mathrm{~h}$ (Fig. I). This is typical of many filamentous fungi grown in liquid culture (Cochrane, 1958). Sporulation started

Table I. Rate of growth of five strains of Aspergillus niger

\begin{tabular}{|c|c|c|c|c|c|}
\hline \multirow{3}{*}{$\begin{array}{l}\text { Incubation } \\
\text { (days) }\end{array}$} & \multicolumn{5}{|c|}{ Strain } \\
\hline & NRRL 346 & NRRL 334 & NRRL 323 & MUBL I & $\mathbf{M}$ \\
\hline & \multicolumn{5}{|c|}{ Mycelial dry weight (mg.) } \\
\hline $\mathbf{I}$ & $7 \pm 6 *$ & II \pm 5 & $18 \pm 7$ & $13 \pm 7$ & $2 \cdot 4 \pm 0 \cdot 3$ \\
\hline 2 & $203 \pm 14$ & $25^{8} \pm 10$ & $241 \pm 2$ & $215 \pm$ II & $83 \pm 3$ \\
\hline 3 & $291 \pm 5$ & $301 \pm 2$ & $313 \pm 2$ & $344 \pm I 3$ & $292 \pm 2$ \\
\hline 4 & $29 I \pm 5$ & $283 \pm 2$ & $269 \pm 4$ & $318 \pm 10$ & $240 \pm 4$ \\
\hline 5 & $284 \pm 0.3$ & $252 \pm 4$ & $246 \pm 2$ & $279 \pm 19$ & $239 \pm 4$ \\
\hline 6 & $283 \pm 3$ & $242 \pm 3$ & $22 I \pm 2$ & $223 \pm 3$ & $186 \pm 2$ \\
\hline
\end{tabular}

on the 3 rd or 4 th day, i.e. at the end of the phase of rapid growth, with the exception of strain NRRL 346, which began to sporulate on the second day. Whether the decrease in dry weight of the mycelium after $72 \mathrm{hr}$ was due to sporulation or to extensive autolysis of the mycelium is not clear. There appeared to be a correlation between sporulation and decrease in mycelial weight, the reproductive phase being presumably stimulated either by exhaustion of the nutrients in the medium or by autolytic products.

Statistical analysis of the data (Table I) indicated that the mycelial dry weights at the end of 3 days of incubation was significantly greater than on the preceding or the following day. In some of the experiments, however, growth was not significantly different between 3 and 4 days, though the average weight of mycelium at the end of 4 days was always lower. Strain NRRL 346 was an exception in that there was no significant decrease in mycelial weight after reaching the maximum at the end of 3 days. 


\section{Response of two strains of Aspergillus niger to Mn deficiency}

Two drops of spore suspension of the two strains MUBL $I$ and $M$ were added to ' minus all', 'minus $\mathrm{Mn}$ ' and 'plus all' media and the flasks incubated at $35 \pm 0.2^{\circ}$. Each treatment had three replicates. One set of flasks were filtered on the 3 rd day and another on the 6th day after inoculation; the results are presented in Table 2.

Both the strains showed a considerable decrease in mycelial yields in the absence of manganese, strain MUBL I showing lesser growth than strain $\mathrm{M}$. In Mn-deficient media both strains produced discontinuous mycelia and there was no sporulation in these Mn-deficient cultures even at the end of 6 days.

Table 2. Mycelial yield of two strains of Aspergillus niger in Mn-deficient cultures at two different incubation periods

\begin{tabular}{lcccccc} 
& \multicolumn{3}{c}{} & \multicolumn{3}{c}{6 days } \\
Strains & $\begin{array}{c}\text { Minus } \\
\text { all }\end{array}$ & $\begin{array}{c}\text { Minus } \\
\text { Mn }\end{array}$ & $\begin{array}{c}\text { Plus } \\
\text { all }\end{array}$ & $\begin{array}{c}\text { Minus } \\
\text { all }\end{array}$ & $\begin{array}{c}\text { Minus } \\
\text { Mn }\end{array}$ & $\begin{array}{c}\text { Plus } \\
\text { all }\end{array}$ \\
MUBL I & 5.8 & $60 \cdot 3$ & $306 \cdot 3$ & $6 \cdot 3$ & $75 \cdot 1$ & $225 \cdot 4$ \\
M & $4 \cdot 9$ & $96 \cdot 0$ & $26 I \cdot I$ & $8 \cdot 5$ & $139 \cdot 7$ & $188 \cdot 6$
\end{tabular}

Table 3. Effect of concentration of Mn on the growth of three strains Aspergillus niger

\begin{tabular}{|c|c|c|c|c|c|c|}
\hline \multirow{2}{*}{$\begin{array}{l}\text { Concentration of } \mathrm{Mn} \\
(\mu \mathrm{g} . / \mathrm{ml} .)\end{array}$} & \multicolumn{3}{|c|}{ Spore inoculum } & \multicolumn{3}{|c|}{ Mycelial inoculum } \\
\hline & NRRL 346 & NRRL 334 & $\begin{array}{c}\text { M } \\
\text { Mycelia }\end{array}$ & $\begin{array}{r}\text { NRRL 346 } \\
\text { ight (mg.) }\end{array}$ & NRRL 334 & $\mathbf{M}$ \\
\hline I. 0.000 & 146 & 150 & 89 & 132 & 87 & 59 \\
\hline 2. 0.001 & 216 & 2 II & 212 & 204 & I IO & 88 \\
\hline 3. 0.002 & 229 & 202 & 252 & 206 & 165 & II5 \\
\hline 4. 0.004 & 259 & 273 & $27 I$ & 237 & 222 & 162 \\
\hline 5. 0.006 & 275 & 310 & 273 & 255 & 257 & I77 \\
\hline 60.008 & 292 & 303 & 259 & 265 & 256 & 185 \\
\hline 7. 0.01 & 291 & 307 & 269 & 263 & 277 & I 87 \\
\hline 8. 0.02 ('plus all') & 298 & 301 & 283 & 266 & 277 & 214 \\
\hline Basal medium ('minus & 5 & 9 & 7 & I I & 8 & 5 \\
\hline
\end{tabular}

Statistical significance by $F$ test at $5 \%$

$\begin{array}{lcc}\text { Strain } & \text { Inoculum:spore suspension } & \text { Inoculum:mycelial suspension } \\ \text { M } & \mathrm{I}, \overline{2,3,6,7,4,5,8^{*}} & \overline{\mathrm{I}, 2,3, \overline{4,5,6,7,8}} \\ \text { MRRL346 } & \mathrm{I}, \overline{2,3}, \underline{4,5,7,6,8} & \mathrm{I}, \overline{2,3}, \overline{5,7,6,8} \\ \text { NRRL 334 } & \mathrm{I}, \underline{3,2, \overline{4,8,6,7,5}} & \overline{\mathrm{I}, 2,3,4, \overline{6,5,7,8}}\end{array}$

* The difference between treatments falling under the same bar are not significant.

Response of five strains of Aspergillus niger to concentration of $\mathrm{Mn}$

The effect of graded quantities of Mn on the growth and sporulation of the five strains was studied under the conditions mentioned above. The required micronutrient elements were added, varying only the concentration of manganese. The $\mathrm{Mn}$ concentrations were $0.00 \mathrm{I}, 0.002,0.004,0.006,0.008,0.01$ and $0.02 \mu \mathrm{g} . / \mathrm{ml}$. Spore and 


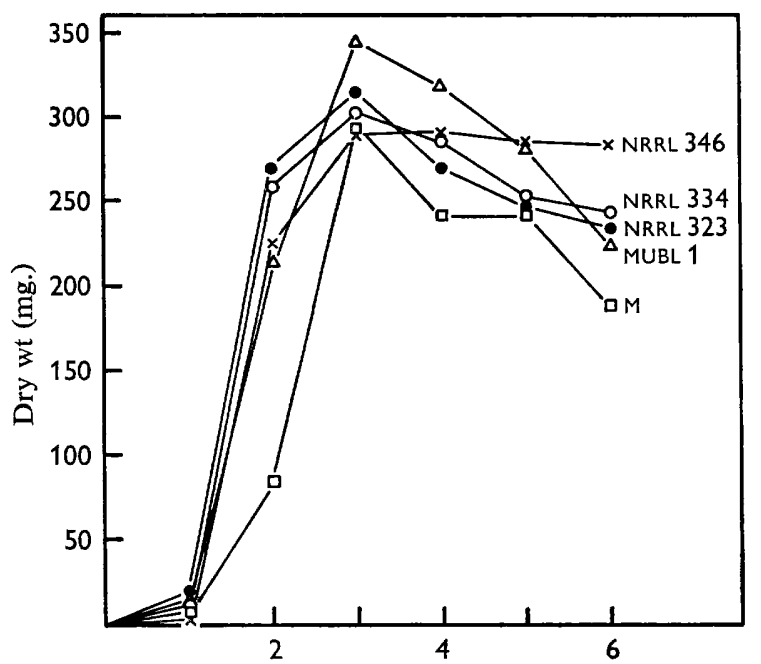

Time (days)

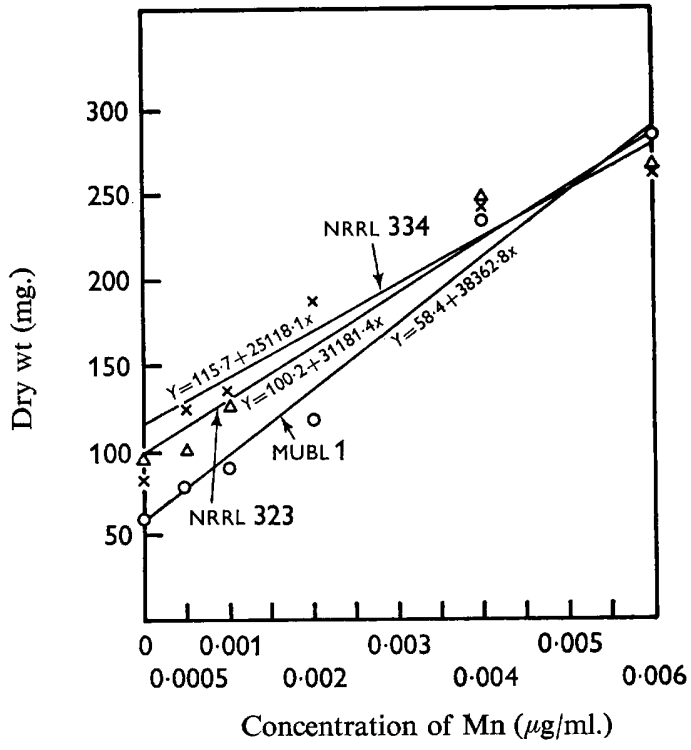

Fig. 2

Fig. I. The rate of growth of five strains of Aspergillus niger in static cultures.

Fig. 2. Regression graphs showing the growth response of Aspergillus niger strains MUBS I, NRRL 323 and NRRL 334 to graded increments in Mn concentration.

Table 4. Effect of concentration of Mn on the growth of three strains of Aspergillus niger $(\mu \mathrm{g} . / \mathrm{ml}$.

\section{Basal medium}

$\begin{array}{ll}\text { I. } 0.0 & 140 \\ \text { 2. } 0.001 & 183 \\ \text { 3. } 0.002 & 266 \\ \text { 4. } 0.004 & 300 \\ \text { 5. } 0.006 & 311 \\ 6.0 .008 & 314 \\ \text { 7. } 0.01 & 309 \\ 8.0 .02 \text { ('plus all') } & 309\end{array}$

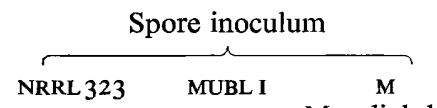

$\overbrace{\begin{array}{c}\text { NRRL323 } \\ \text { weight (mg.) }\end{array}}^{\text {MUcelial inoculum I }} \quad$ M

('minus all') alone

Statistical significance by $F$ test at $5 \%$

$\begin{array}{lcc}\text { Strain } & \text { Inoculum:spore suspension } & \text { Inoculum:mycelial suspension } \\ \text { M } & \mathrm{I}, \overline{2,3,6,4,7,5,8} & \mathrm{I}, 2, \overline{3,4,5,7,6,8} \\ \text { NRRL 323 } & \mathrm{I}, 2, \overline{4,7,8,5,6} & \mathrm{I}, 2, \overline{3,4,4,5,6,7} \\ \text { MUBL I } & \mathrm{I}, 2,3, \overline{8,6,7,8} & \overline{\mathrm{I}, 2, \overline{3,4,8,6,5,7}}\end{array}$

mycelial inocula were separately used. In all these experiments the mycelial mats were harvested at the end of 3 days of incubation when maximum mycelial yield was obtained. The effect of $\mathrm{Mn}$ on sporulation was observed in separate sets of flasks which 
were incubated for 6 days. Three strains were compared in each experiment, using either spore or mycelial inocula. The combination of strains used were as follows: (I) M, NRRL 346 and NRRL 334, (2) M, NRRL 323 and MUBL I. All strains showed a gradual increase in mycelial production with increasing concentration of manganese (Tables 3, 4). Statistical analyses indicated that strain $M$ does not show significant variation in mycelial dry weight with variation in Mn concentration. In a few experiments, however, there was a significant increase in dry weight with 0.001 and 0.002 $\mu \mathrm{g} . / \mathrm{ml}$. Strain NRRL 346 showed difference in weight only between 'minus $\mathrm{Mn}$ ' and $0.00 \mathrm{I} \mu \mathrm{g}$. Mn $/ \mathrm{ml}$. and between 0.002 and $0.004 \mu \mathrm{g}$. Mn $/ \mathrm{ml}$. Strain NRRL 334 was similar to strain NRRL 346 in its response when spore inoculum was used; however, significant differences between various levels of $\mathrm{Mn}$ were obtained with mycelial inoculum. Strains NRRL 323 and MUBL I showed significant increase in mycelial dry weight with increasing $\mathrm{Mn}$ concentration up to 0.004 and $0.006 \mu \mathrm{g} . / \mathrm{ml}$., respectively, when spore inocula were used; mycelial inocula did not improve the response of these two strains.

Table 5. Effect of concentration of Mn on the growth of five strains of Aspergillus niger (mycelial inoculum)

Concentration of $\mathrm{Mn}$
$(\mu \mathrm{g} . / \mathrm{ml}$.
I. 0.0000
2. 0.0005
3. 0.001
4. 0.002
5. 0.004
6. 0.006
7. 0.02 ('plus all')

Basal medium ('minus all') alone

\begin{tabular}{|c|c|c|c|c|}
\hline \multicolumn{5}{|c|}{ Strain } \\
\hline NRRL 346 & NRRL 334 & NRRL 323 & MUBL I & \multirow[t]{2}{*}{ M } \\
\hline \multicolumn{4}{|c|}{ Mycelial dry weight (mg.) } & \\
\hline 171 & 82 & 94 & 66 & 77 \\
\hline 152 & 125 & IOI & 78 & 78 \\
\hline 197 & 133 & 127 & 9 I & 102 \\
\hline 219 & 187 & 185 & 118 & I 64 \\
\hline 244 & 243 & 250 & 236 & I 57 \\
\hline 249 & 263 & 265 & 279 & 167 \\
\hline 272 & 288 & 294 & 348 & I9I \\
\hline Io & 8 & 13 & 15 & 9 \\
\hline
\end{tabular}

$\begin{array}{ll}\text { Statistical significance by } F \text { test at } 5 \\ \text { NRRL } 346 & \text { Not significant } \\ \text { NRRL 334 } & \text { A, B, C, D, E, F, G } \\ \text { NRRL } 323 & \overline{A, ~ B, ~ C, ~ D, ~ E, ~ F, ~ G ~} \\ \text { MUBL I } & \overline{\text { A, B, C, D, E, F, G }} \\ \text { M } & \text { A, B, C, D, E, F, G }\end{array}$

Two features were observed in the above experiments: (I) there was no marked differences in the mycelial dry weight of any of the strains tested above $0.006 \mu \mathrm{g}$. $\mathrm{Mn} / \mathrm{ml}$; (2) in the majority of the experiments there was a significant difference between 'minus $\mathrm{Mn}$ ' and $0.00 \mathrm{I} \mu \mathrm{g}$. $\mathrm{Mn} / \mathrm{ml}$. Hence the response of all the strains was compared for the following manganese concentrations: $0.0005,0.001,0.002$, $0.004,0.006$ and $0.02 \mu \mathrm{g} . / \mathrm{ml}$. The data presented in Table 5 confirmed the earlier observations on the response of all the strains. In addition, there was no significant difference between the growth obtained at $0.0005 \mu \mathrm{g}$. Mn/ml. and 'minus $\mathrm{Mn}$ ' cultures of strain M, MUBLI, and NRRL 323. Strain NRRL 334 showed no difference in growth between 0.0005 and $0.00 \mathrm{I} \mu \mathrm{g}$. Mn $/ \mathrm{ml}$. On statistical analysis, the relationship 
between concentration of Mn and growth exhibited by MUBL I and NRRL 323 was found to follow a linear regression (Fig. 2) that is real and highly significant at both $5 \%$ and I $\%$ levels, the observed $F$ value being I 6 I 34 and $43 \cdot$ I respectively (The Table value of $\mathrm{F}$ at $5 \%$ is $7 \cdot 7 \mathrm{I}$ and at $\mathrm{I} \%, 2 \mathrm{I} \cdot 2$ ) with degrees of freedom I and 4 . For strain NRRL 334, the linear regression is just significant at $5 \%$ level only, the observed value of $F$ being $8 \cdot 05$.

No attempt was made in the present work at a quantitative evaluation of sporulation in relation to $\mathrm{Mn}$ concentration. Visual observation indicated that sporulation started only at the concentration of $0.006 \mu \mathrm{g}$. $\mathrm{Mn} / \mathrm{ml}$. and that there was a good gradation in degree of sporulation from 0.006 to $0.02 \mu \mathrm{g}$. Mn/ml. for all the strains.

\section{DISCUSSION}

A study of the growth curves of the five strains of Aspergillus niger used in relation to sporulation suggests a correlation between growth and reproduction. Sporulation started towards the end of the phase of rapid growth in all strains except in NRRL 346 and the increase in sporulation was accompanied by a decrease in dry weight of mycelium. Few studies have considered critically the relation of reproduction to growth phases. The data of Robinson (1926) for Sporodinia grandis Link indicated that in static culture, spores usually developed at the end of the phase of rapid growth; although spores may appear earlier (Cochrane, 1958).

In the absence of manganese, Aspergillus niger strain $M$ showed a reduction in mycelial yields of more than $60-70 \%$ of that in 'plus all' cultures; MUBL I showed a decrease of more than $75 \%$, whereas the other three strains showed only a $50 \%$ decrease in growth. Nicholas \& Fielding (195I) and Nicholas (1952) did not obtain decreases in mycelial yields of $A$. niger strain $\mathrm{M}$ in the absence of $\mathrm{Mn}$, and SaraswathiDevi (1954, I962) obtained I $20 \%$ growth in Mn-deficient cultures as compared to the 'plus all' cultures. The higher mycelial yields in the absence of Mn might probably be explained by the fact that the mycelial dry weights were measured on the 6th day when 'plus all' cultures had sporulated abundantly and hence gave a lower mycelial dry weight than the Mn-deficient cultures which showed neither sporulation nor decrease in mycelial yields. Donald et al. (1952b) indicated the inefficiency of the purification procedure adopted by Nicholas (1950, 1952). Presumably this was only one of the contributory factors for masking of the Mn-deficiency symptoms, since SarawathiDevi (1954, 1962) had used the more efficient purification method of Donald et al. $(1962 b)$ which was also used in the present work. A feature common to all the investigations in which the absence of Mn gave no decrease in mycelial yields was the use of a high salt concentration in the basal medium (about $8 \cdot 75-9.5$ g./1.) and the addition of very high concentrations of micronutrient elements. A high salt concentration, although resulting in tough twisted mycelial strands instead of smooth fluffy growth, does not prevent the decrease in mycelial yields in the absence of $\mathrm{Mn}$, although Donald et al. (1952 b) did obtain more than $60 \%$ decrease with a concentration of $8 \mathrm{~g}$. $/ 1$. However, it is evident from the data of Steinberg (I936) that increasing the concentration of trace elements beyond an optimum value either at $\mathrm{pH} 7.35$ or at $\mathrm{pH} 8.04$ resulted in the lowering of the growth ratio (yield with element : yield without element) besides having a toxic effect on sporulation. Hence it is probable that a high trace element concentration also contributes to masking the Mn-deficiency symptoms. 
The comparison of the response of the five strains of Aspergillus niger to Mn concentration indicates that although all the strains showed a graded increase in mycelial yields, the effective range for assay of Mn was greater with strain MUBL I than with the other strains tested, the range lying between $0.00 \mathrm{I}$ and $0.006 \mu \mathrm{g} . \mathrm{Mn} / \mathrm{ml}$. If sporulation could be measured precisely, the range of concentrations between 0.006 and $0.02 \mu \mathrm{g} . \mathrm{Mn} / \mathrm{ml}$. could also be included for purposes of assay.

Aspergillus niger MUBL I strain appears to be an ideal test organism for bioassay of manganese. This method has been found to be roo-fold more sentive than the well known spectrophotometric method with potassium periodate or ammonium persulphate as the oxidizing agent for conversion of $\mathrm{Mn}$ into $\mathrm{MnO}_{4}$ (Sulochana, 1967).

Under the same cultural conditions the possible use of strain MUBL I for $\mathrm{Cu}$ and Mo assays was also studied; satisfactory results were obtained even for Mo series for which neither $\mathrm{Al}_{2} \mathrm{O}_{3}$ purification nor the $\mathrm{H}_{2} \mathrm{~S}$ co-precipitation method of Hewitt \& Hallas (195I) was reported to be satisfactory (Saraswathi-Devi, I954).

Aspergillus niger MUBL I has been used for assay of $\mathrm{Mn}$ in soils, plant tissues, human tissues, sera and blood; the standard series repeated every time with the samples have been consistently reproducible. The results of bioassay of manganese in cottongrowing soils will be reported elsewhere.

Grateful thanks are due to Professor T. S. Sadasivan for his interest and encouragement, and to Professor T. C. Vanterpool for critically reading the manuscript. We are thankful to the Northern Regional Research Laboratory, Peoria, Illinois, U.S.A., for lyophilized cultures of Aspergillus niger strains NRRL 323, 334 and 346. Thanks ae due to Indian Council of Medical Research and the Indian Council of Agricultural Research for grants during the tenure of which this work was done.

\section{REFERENCES}

BaIley, N. T. J. (196I). Statistical Methods in Biology. London: The English Universities Press.

Cochrane, V. W. (1958). Physiology of Fungi. New York: John Wiley and Sons, Inc.

Donald, C., PASSEY, B. I. \& Swaby, R. J. (1952 $a$ ). Bioassay of available trace metals from Australian soils. Aust. J. agric. Res. 3, 305.

Donald, C., Passey, B. I. \& Swaby, R. J. (1952 $b$ ). A comparison of methods for removing trace metals from microbiological media. J. gen. Microbiol. 7, 211.

FreEMAN, H. A. (1956). Industrial Statistics. New York: John Wiley and Sons, Inc.

HewitT, E. J. \& Hallas, D. G. (I95I). The use of Aspergillus niger (van Tiegh.) m strain as a test organism in the study of molybdenum as a plant nutrient. Pl. Soil. 3, 366.

Mulder, E. C. (1948). The microbiological estimation of copper, magnesium and molybdenum in soil and plant materials. Analytica chim. Acta 2, 793.

Nicholas, D. J. D. (1950). Use of Aspergillus niger for determining magnesium, copper, zinc and molybdenum in soil. J. Sci. Fd Agric. 1, 339.

Nicholas, D. J. D. (1952). The use of fungi for determining trace metals in biological materials. Analyst 77, 629.

Nicholas, D. J. D. \& Fielding, A. H. (195I). The use of Aspergillus niger (M) for the determination of magnesium, zinc, copper and molybdenum available in soils to crop plants. J. hort. Sci. 26, I25.

Niklas, H. \& Hirschierger, W. (1924). Eine neue Methode zur raschen Ermittlung der Phosphorsäure-Bedürftigkeit unserer Böden. Z. angew. Chem. 37, 955.

PAterson, D. D. (1939). Statistical Technique in Agricultural Research. New York: McGraw-Hill Book Co. Inc.

RobINSON, W. (1926). On some features of growth and reproduction in Sporodinia grandis Link. Trans. Br. mycol. Soc. ro, 307. 
Saraswathi-Devi, L. (1954). Bioassay of heavy metals by Aspergillus niger-sensitivity of a new strain. Proc. Indian Acad. Sci. 40 B, I.

Saraswathi-Devi, L. (I958). Problems and techniques involved in trace elements essentiality studies with fungi-a critical appraisal. Proc. Indian Acad. Sci. 48 B, 96.

SARASWATHI-DEVI, L. (1962). Soil conditions and wilt diseases: bioassay of cotton soils of the Madras state for trace elements. Phytopath. Z. 45, 289.

Steingerg, R. A. (1936). Some effects of the heavy metals essential for the nutrition of Aspergillus niger upon its growth. Am. J. Bot. 23, 227.

SteinBERG, R. A. (1939). Relation of carbon nutrition to trace element and accessory requirements of Aspergillus niger. J. agric. Res. 53, 749.

Steinberg, R. A. \& Bowling, J. D. (1939). Optimum solutions as physiological reference standards in estimating nitrogen utilization by Aspergillus niger. J. agric. Res. 58, 717.

Sulochana, C. B. (1967). Manganese in biological samples. Curr. Sci. 36, 508. 
